anales de psicología, 2018, vol. 34, $\mathrm{n}^{\circ} 2$ (mav), 332-339 http://dx.doi.org/10.6018/analesps.34.2.299371
(C) Copyright 2018: Editum. Servicio de Publicaciones de la Universidad de Murcia. Murcia (Spain) ISSN print edition: 0212-9728. ISSN web edition (http://revistas.um.es/analesps): 1695-2294

\title{
Reconceptualising workplace resilience - A cross-disciplinary perspective
}

\author{
Caroline Rook ${ }^{1 *}$, Lee Smith ${ }^{2}$, James Johnstone ${ }^{2}$, Claire Rossato ${ }^{3}$, Guillermo Felipe López Sánchez ${ }^{4}$, \\ Arturo Díaz Suárez ${ }^{4}$, and Justin Roberts ${ }^{2}$ \\ 1 Henley Business School, Greenlands Campus (United Kingdom). \\ 2 The Cambridge Centre for Sport and Exercise Science, Anglia Ruskin University (United Kingdom). \\ 3 Department of Life and Sport Sciences, University of Greenwich (United Kingdom). \\ 4 Faculty of Sports Sciences, University of Murcia (Spain).
}

\begin{abstract}
Título: Reconceptualización de la resiliencia en el lugar de trabajo - Una perspectiva interdisciplinar.

Resumen: Las situaciones estresantes, la presión laboral y los contratiempos son parte de la organización de la vida contemporánea. La naturaleza dinámica de los avances tecnológicos y la globalización del comercio conduce a mayores presiones competitivas y a un cambio constante. Las respuestas de las personas a estas complejas circunstancias son muy diferentes. Algunos se recuperan y se adaptan a los nuevos retos y adversidades, mientras que otros ven su salud seriamente afectada. Aunque la resiliencia es reconocida como un asunto crucial en el lugar de trabajo, la prevalencia de casos de estrés laboral y depresión se ha mantenido constante durante más de diez años. La investigación en resiliencia dentro de la Psicología Aplicada normalmente se ha centrado en el aspecto psicológico del funcionamiento de la persona. Por tanto, los entrenamientos o intervenciones para mejorar la resiliencia se han centrado solo en un área. El objetivo de este artículo es construir una conceptualización comprensiva de la resiliencia en el lugar de trabajo, a fin de ayudar al diseño de intervenciones específicas y desarrollar un modelo para avanzar en el área de investigación en su conjunto. Una comprensión y un enfoque interdisciplinar de la resiliencia individual en el lugar de trabajo permitiría comprender mejor el mecanismo de por qué algunas personas se recuperan de eventos adversos, mientras que el bienestar de otros disminuye. Proponemos un enfoque de la resiliencia que tenga en cuenta aspectos psicológicos (cognitivos y emocionales) y fisiológicos (cardiovasculares, gastrointestinales y metabólicos).

Palabras clave: Resiliencia; individual; lugar de trabajo; salud; interdisciplinar.
\end{abstract}

\section{Introduction}

The current working environment is turbulent and complex owing to increasing globalisation and digitalisation of the business world. The resulting competition and continuing change in the workplace (through technological advances and business models) places increasing pressure on those in employment. As this dynamic working environment is seemingly becoming the norm, resilience is a "strategically important organizational behaviour for success, growth, and even survival" (King, Newman, \& Luthans, 2016, p. 782) for organisations and the people working within them. However, people's responses to the described challenging circumstances vary widely. Some bounce back and learn from increasing challenges, adversity, and constant change, for others their healthy functioning is significantly impaired.

What constitutes resilience and which correlates influence resilience is currently not well understood. This may be owing to differences in definitions of resilience. In the area of Applied Psychology and Organisational Behaviour a

* Correspondence address [Dirección para correspondencia]:

Caroline Rook. Henley Business School, Greenlands Campus. Greenlands, Reading, Henley-on-Thames RG9 3AU (United Kingdom).

E-mail: c.rook@henley.ac.uk
Abstract: Stressful situations, performance pressure, and setbacks are part of contemporary organizational life. The dynamic nature of technological advances and globalisation of business leads to tougher competitive pressures and constant change. People's responses to these challenging circumstances vary widely. Some bounce back and adapt to increasing challenges and adversity, others' healthy functioning is significantly impaired. Even though resilience is recognised as a crucial issue in the workplace, the rates of new cases of work-related stress and depression have remained broadly flat for more than 10 years. Resilience research within Applied Psychology typically focuses on the psychological domain of a person's functioning. This means that also resilience trainings or interventions focus on only one area. The present paper aims to build a comprehensive conceptualization of workplace resilience ultimately to assist in informing targeted intervention and in developing a model to move the research area forward as a whole. A cross-disciplinary understanding of and approach to individual resilience in the workplace would allow to better understand the mechanism of why some people bounce back from adverse events whereas others' well-being declines. We propose a resilience framework with antecedents considering psychological (cognitive and emotional) and physiological correlates (cardiovascular, gastrointestinal and metabolic).

Keywords: Resilience; individual; workplace; health; cross-disciplinary.

number of different definitions of resilience have been used. Some scholars understand resilience to be a dynamic process while others see it as a trait (King et al., 2016). All definitions however describe resilience as the ability to deal with and adjust to adversity (i.e., bouncing back). In regards to factors influencing the ability to cope and adjust to adversity, research has mainly focused on personal characteristics such as self-efficacy (see King et al., 2016). The Psychological Capital concept (Luthans, 2002) has been particularly influential in recent research on how to build and maintain personal resilience at work (Linnenluecke, 2017).

As resilience research within the Applied Psychology and Organsitional Behaviour domain typically focuses on one aspect of a person's functioning, that is the psychological domain (for an overview, see Linnenluecke, 2017), also resilience trainings or interventions focus on only one area (see Robertson, Cooper, Sakar, \&Curran, 2015). However, cases of sudden collapse due to extreme fatigue (e.g., Lloyds Bank CEO Antonio Horta-Osorio in 2011; see Rook, Hellwig, \& Florent-Treacy, 2015) support the notion that physical health (as well as psychological health) of people at work plays a crucial role in workplace health and performance. Indeed, health should be considered holistically as different functions of the human body and mind influence, and interact with, 
each other (e.g., see Psychoneuroimmunology; Irwin \& Vedhara, 2005). However, the bio-psychological and biophysiological aspects of a person's functioning have not been previously acknowledged in workplace resilience.

In the area of Health Psychology, conversely, an integrative approach to resilience has been promoted almost a decade ago. For example, Zautra, Hall, and Murray (2008, p. 42) define resilience as "an outcome of successful adaptation to adversity", and that more resilient individuals demonstrate a "greater capacity to quickly regain equilibrium physiologically, psychologically, and in social relations following stressful events". However, workplace resilience is unlikely to be so 'linear', with stressful events occurring randomly, sporadically, and over prolonged periods. In many respects this could be likened to the stress imposed with physical training. Athletes often report feeling 'overreached' during and following demanding or intensive training bouts and during acute training periods, i.e. in preparation for an event.

When the physical system is stressed beyond reasonable tolerance, adaptive mechanisms may become dysfunctional, leading to dysregulation or low-grade maladaptation. Over time, this inability to maintain homeostasis can lead to progressive deterioration in both short-term recovery processes and longer-term gains to training; ultimately a state of overtraining, or rather, underperformance can manifest (Halson et al. 2003; Shepard, 2001; Smith, 2003a). For people at work, the notion of overtraining might be similar to notions of prolonged distress, leading eventually to burnout. Indeed, to cope with continuous and also unexpected stressful events, resilience trainings aim to develop the capacity of an individual to bounce back (preventative measures) (see Robertson et al., 2015).

The ability to manage stress and maintain high well-being is a core performance indicator, as evidenced by the recent UK government initiative to improve its measurement and systematic consideration in decision-making at societal, organisational, and individual levels (Office for National Statistics, n.d.). The increasing costs of stress through sickness absence and performance loss of employees have been widely reported (Dewe \& Cooper, 2012). Psychological strain is one outcome of work stress (van der Doef \& Maes, 1999). Prolonged work pressures lead to fatigue and burnout (Leiter \& Maslach, 2004; Serrano-Gisbert, Garcés-de-Los-Fayos, \& Hidalgo-Montesinos, 2008), which, in turn, result in sickness absence which impacts not only on the individual but also on the performance of the organisation. Furthermore, psychosocial stress has been shown to be a risk factor for coronary heart disease (Hamer, Endrighi, Venuraju, Lahiri, \& Steptoe, 2012). Indeed, one could argue, that resilience can be regarded as a key characteristicof a successful employee. Levels of individual resilience are likely to determine who succeeds and who fails in the contemporary dynamic and competitive world of work.

However, even though individual resilience is recognised as a crucial issue in the workplace, the rates of new cases of work-related stress and depression have remained broadly flat for more than 10 years (HSE, 2016). It appears that creating a resilient workforce is highly challenging. This is likely to be owing to limitations in current knowledge and thinking. Indeed, the specific mechanisms that link work performance to health are largely unknown and thus it is not possible to implement targeted interventions. Therefore, the present paper aims to build a comprehensive conceptualization of workplace resilience ultimately to assist in informing targeted interventions and developing models to move the research area forward as a whole.

We aim to integrate cross-disciplinary understandings of and approaches to individual resilience in the workplace in order to better understand the mechanism of why some people bounce back from adverse events whereas others' well-being declines (Hobfoll et al., 2007; Castellano-Tejedor, Blasco-Blasco, Pérez-Campdepadrós, \& Capdevila-Ortís, 2014). We therefore contribute to the understanding of factors and adaptive processes that promote individual resilience. We aim to answer the following the question: Are there distinct aspects to consider with regard to comprehensively conceptualizing resilience of individuals in the workplace?

Our cross-disciplinary perspective allows exploring resilience holistically while connecting research from different sciences. In different fields empirical research has explored the impact of resilience on personal health (and performance). However, each field respectively focused on one aspect of human functioning. For Applied Psychology and Organizational Behavior in particular, this means that the mechanisms of how and when resilience leads to improved health and work performance are not well understood. Furthermore, effective training methods that maximise the increase in resilience by addressing all aspects of it cannot be designed. The framework developed in this paper therefore makes two contributions. First, the framework is based on a comprehensive integration of multiple literatures (i.e., Psychology and Physiology) to identify key components of individual resilience. Second, the framework contributes to the understanding of the mechanisms how resilience is created and leads to improved health and work performance. Future studies can test elements of the proposed framework.

We therefore first explore insights on individual workplace resilience from the Applied Psychology literature and then turn to Psychology and Physiology, before we then build our resilience conceptualization based on the insights from these different sciences. We conclude by outlining a future research and practice agenda that will address the need to understand and therefore maintain resilience on a multidisciplinary level that can address specific mechanisms that create resilience and link it to healthy functioning at work.

\section{Current knowledge on individual workplace resilience in the Applied Psychology literature}

Research on resilience in the area of Applied Psychology and Organizational Behaviour has its roots in Clinical and Devel- 
opmental Psychology. There are several longer standing concepts that are linked with resilience such as hardiness. Windle (2011) argued that "the defining point which distinguishes hardiness from resilience is that it is a stable personality trait whereas resilience is viewed as something dynamic that will change across the lifespan" (p. 163). However, in the Organizational Behaviour domain the resilience concept has been defined as a trait or capacity (e.g., Jackson, Firtko, \& Edenborough, 2007; Tugade \& Fredrickson, 2004) and as a dynamic process (e.g., Friborg, Hjemdal, Rosenvinge, \& Martinussen, 2003). In general, scholars agree that resilient individuals have the capacity to deal with change in a positive manner, they bounce back from adversity (Fredrickson, 2001). In Positive Organisational Behaviour, the resilience definition includes in addition the ability to build strengths and virtues for sustainable high performance and well-being based on experiencing and coping with the adverse experience (Luthans, Youssef, \& Avolio, 2007). Resilience therefore includes two aspects: the adjustment to adversity and bouncing back and sometimes even thriving through adversity. Related constructs are flexibility, agility, and adaptability; however, resilience takes place because of adversity.

Advances on key personal characteristics of resilient individuals have been made in particular in the area of Positive Organisational Behaviour (King et al. 2016; Linnenluecke, 2017). There, resilient individuals are described as knowing their strengths and weaknesses, creating opportunities, and knowing how to navigate uncertainty and change (Luthans et al., 2007). They also know how and when pressures at work turn into stress and how to rebalance themselves. They are able to deal with the demands placed upon them, especially when having to deal with constantly changing priorities and a heavy workload. To learn from setbacks requires a positive attitude and emotion regulation abilities (Cartwright \& Cooper, 2009). A positive attitude includes having a constructive conceptual orientation through a strong sense of purpose, core values, and a genuine vision. Emotion regulation includes impulse control, causal analysis, self-efficacy, realistic optimism, empathy, and reaching out to others. Indeed, insights into key workplace antecedents of resilience could be drawn from the existing literature on workplace well-being. Where antecedents of well-being have been established in terms of workplace characteristics (opportunity for personal control, opportunity for skill use, externally generated goals, environmental clarity, contact with others, reward, physical security, valued social position, career outlook, supportive supervision and other social resources; Demerouti, Bakker, Nachreiner, \& Schaufeli, 2001; Hackman \& Oldham, 1975; Herzberg, 1959; Johnson \& Hall, 2008; Karasek \& Theorell, 1990; Morgeson \& Humphrey, 2006; Warr, 2003) and psychological antecedents (personality traits such as extraversion and neuroticism, cognitive behaviour such as comparisons in relation to work demands of fellow employees, and personal resources such as self-efficacy, accepting reality, meaning or spirituality, optimism, selfesteem; Daniels, 2011; Diener, 1994; Hobfoll, 1989; Warr and Clapperton, 2009; Warr, 2013).For a recent overview of key studies on factors impacting on an individual's resilience, please see Linnenluecke (2017).

An integration of different theoretical perspectives on how antecedents of resilience are developed and actual mechanisms that lead to the ability to sustain well-being and performance during periods of stress and to recover quickly is needed to understand key mechanisms of developing and maintaining resilience. We therefore now turn to reviews of the current knowledge on individual resilience in the fields of Psychology and Physiology. We first explore psychophysiological conceptualizations of individual resilience.

\section{Psychophysiological Conceptualisations of Individual Resilience}

As previously discussed, workplace resilience is an interdisciplinary construct (King et al., 2016), which encompasses not only psychological elements but also physiological factors. As shown in the previous section, this however, is seldom examined within the Applied Psychology literature. Within this section, it is proposed that physiological constructs are related to coping behaviours and therefore are an important factor that should be considered when examining resilience.

In Health Psychology, Richardson, Neiger, Jensen, and Kumpfer (1990) suggested that resilience is "the process of coping with disruptive, stressful, or challenging life events in a way that provides the individual with additional protective and coping skills than prior to the disruption that results from the event" (p.34). Also, in working stress prevention, the training of coping skills is fundamental, and early resiliency literature suggested that cardiovascular responses have an interaction with behavioural change and coping behaviours (Orbrist, 1976). Cardiovascular responses within this context represent adjustments in hemodynamic and its distribution that occurs to meet the metabolic requirements potentially or actually demanded by the task or activity the individual is facing. In addition, Orbrist (1976) suggested that coping behaviours had an association with cardiovascular reactivity. Active coping refers to trying to cope with the situation. For example, feeling pain in a situation, an individual might try to function despite the pain, whereas passive coping would refer to withdrawing and surrendering control over the pain. Passive coping was linked to changes in total peripheral resistance (TPR) and active coping was linked to an increase in cardiac output (CO). It may be suggested that labile hypertension is associated with active coping; whereas essential hypertension is associated with passive coping and that the accompanying cardiovascular responses that are associated with these coping strategies are linked with challenge (active coping) and Threat (passive coping; Blascovich \& Mendes, 2000)

Furthermore, Dienstbier (1989) within the Arousal and Physiological Toughness model focused upon two physiological responses and associated these with the labels challenge 
and stress (Threat). Dienstbier (1989) suggested that the activation of the sympathetic nervous system (SNS) is related to a challenge, suggested to cause sympathetic-adrenomedullary activation (SAM). If the SAM is aroused this causes a release of adrenaline and noradrenaline (endocrine response). The stress (Threat) is said to be associated with SAM but also 'pituitary adrenal cortical arousal (PAC)'. Dienstbier (1989) suggested that this interaction features the pituitary gland, which releases adrenocorticotropin (ACTH) into the blood, and the adrenal cortex is stimulated to release cortisol (endocrine response).

This notion has also been explored within the Biopsychosocial Model or BPSM (Blascovich \& Mendes, 2000). Within the BPSM there appears to be three processes that lead to a challenge or threat appraisal; the first being if the task holds any relevance; the second, how an individual perceives the demand of the relevant task (Blascovich \& Mendes, 2000); and thirdly, whether the individual perceives they have enough resource to cope with the demand. In addition the BPSM suggests that there is a physiological component to appraising a situation as a challenge or a threat. In particular, cardiovascular responses and endocrine responses (e.g. 'SAM and 'PAC' activation) are suggested to indicate whether an individual has appraised the situation as a challenge or threat. Specifically, a challenged state is characterised by an increase in CO and a decrease in TPR due to the vasodilatation of the arteries associated with the hormonal release of adrenaline and noradrenaline. Collectively, this results in lower TPR and a higher CO compared to that of a threat. In contrast, a threat appraisal results in cardiac and vascular resistance, an increase in blood pressure due to the release of adrenaline, noradrenaline and cortisol release. Cardiovascular responses to challenge and threat are identified as predominantly TPR and CO. Importantly from this perspective, cardiovascular responses are considered to be reliable indices of challenge and threat respectively, given that appraisals may occur automatically and outside of individuals' awareness (Blascovich \& Mendes, 2000).

To summarise, if coping mechanisms are associated with cardiovascular and endocrine responses and how an individual appraises a stressful scenario (Challenge or Threat) and resilience is defined by the process of coping (Richardson et al., 1990), it is necessary to exam further the physiological responses associated with coping behaviours and behavioural change (Orbrist, 1976) as outlined within this section. Indeed, in physical and physiological studies, the physiological adaptations in the body system to challenges are not only studied but also put into concrete athlete training methods. In the next section, we explore this more closely.

\section{Physical and Physiological Conceptualisations of Individual Resilience}

In the area of life sciences, the adaptive functionality is a central component of resilience and progressive training is needed to build resilience. Athletes often train according to scientifically demonstrated principles whereby 'challenge to the system' through various types of training provoke transient fatigue (Issurin, 2010). This results in physiological adaptations in the body systems (cardiovascular, respiratory, immune, muscle, hormonal etc.) in a gradual manner as a means to compensate for provoked physical challenge. The concept of 'supercompensation' in athletic training highlights the importance of 'new thresholds of tolerance' being reached in response to both singular and regular bouts of training (Smith, 2003b). If the training is of a suitable or substantial manner (based on frequency, duration, and specificity), the athlete reaches new levels of self-capability. The underlying result: an improved capacity to tolerate higher levels of demand, leading to improved performance.

Such principles should be considered inherent in the model of individual workplace resilience (Doring et al., 2013; Groppel, 2000) because whilst psychological traits are crucial in how individuals mentally bounce back from adversity or channel processes or strategies to cope or thrive with different circumstances (see also concept of mental toughness in Sports Psychology; Jones, 2002), such traits may well be underlined through (or overlap with) the physical function of the individual. When comparing athletes of different levels of experience (for example, trained versus novice), it is clearly apparent that both the fundamental capacity (maximal fitness level, relative muscle strength, level of flexibility) and relative efficiency (heart rate during exercise, ability to use energy fuels economically, capability to sustain power outputs over prolonged periods) differentiate tolerance levels between the two groups. An efficient endurance athlete, for example, will be able to execute a higher power output, with more economic pacing strategies, using less carbohydrate as fuel, with a lower relative heart rate, and more efficient muscle contractile mechanisms than a less trained counterpart. More importantly, if resilience is defined according to recovery rates, a more efficient athlete will have a system physically 'primed' to respond quickly to acute stressful periods (i.e., response to exercise).

With this in mind, it is proposed that workplace resilience should be closer associated with athletic resilience. In other words, physical activity and exercise training play a central role in improving physical health (function) and physiological efficiency (adaptability). It is the combination of physical and physiological states, we believe, that result in greater individual resilience within the workplace.

With increasing prevalance in cardiometabolic disease (Kelli, Lassas, \& Lattouf, 2015), there is current interest in workplace health strategies designed to increase physical activity. Physical inactivity (not meeting physical activity guidelines; Smith, Ekelund, \& Hamer, 2015) and lower fitness states are associated with poor health profiles (e.g., hypertension, raised cholesterol, cancer, obesity, diabetes, and poor mental health). Sleep quality has also been found to impact on health (López-Sánchez, López-Sánchez, \& Díaz-Suárez, 2016; von Bonsdorff et al., 2017). Current research indicates 
that chronic stress (e.g., workplace demands) may be a central factor leading to physiological dysregulation of key systems of the body (e.g., metabolic, hormonal, immune). Such 'dysregulation' may play a central role in development of poor health and chronic disorders, leading to lower resilient states, reduced ability to recover from an acute stressor, and amalgamated maladaption (likened to chronic fatigue syndrome; Shephard, 2001). Physical fitness may provide a mechanistic 'buffer' to dealing with demanding, challenging or intensive periods of workplace stress.

Improved physical function through exercise training has been shown to result in improved stress responses (Salmon, 2001; Southwick \& Charney, 2015), involving the hypothalamic-pituitary-adrenal (HPA) axis. Whilst an acute stress response (increased stress hormones, elevated heart rate, blood pressure and blood glucose) is important for rapid responses (such as mental alertness, motivation, concentration), it would seem that preventing 'overreactivity' via quick termination of such stress responses is a key factor in adaptive resilience (Silverman \& Deuster, 2014). An enhanced parasympathetic response has been shown to enhance antiinflammatory processes, which may be acutely associated with recovery adaptations to exercise. It would appear that when the system is in a state of 'over-stress', i.e., when pushed beyond reasonable tolerance or due to coactivators (unaccustomed workload, intensive exercise), a prolonged recovery period may be required leading to both 'low grade inflammation' and gradual, but chronic dysregulation.

Coupled with this, low levels of activity, high levels of sitting, and low physical fitness is associated with not only increased weight gain (i.e., body mass index), but the potential for higher central adiposity (López, González, \& Díaz, 2016; Smith et al., 2015; Tlucakova et al., 2016; Vespalec, Pavlík, Zvonař, \& Zeman, 2016; Vespalec, \& Zvonař, 2016). If resilience is closely linked with 'low grade inflammation' interring with recovery or adaptive mechanisms, then metabolic balance (reduced visceral fat) and reduced production of 'provocative' cytokines (e.g. interleukin-6, C-reactive protein) could be intrinsically associated with an active lifestyle. This further relates to the importance of physical exercise in the prevention of workplace resilience development and in the reduction of cardio-metabolic risk factors (Depres, 2006; Zurita-Ortega et al., 2016).

Two final areas that are of current interest are how exercise training influences i) brain function and ii) gut function. Regular training has been shown to increase levels of brain derived neurotrophic factor (BDNF) which influences both "behavioural and metabolic responses to various challenging environments" (Silverman \& Deuster, 2014, p.6). In particular, cardiovascular training has been shown increase in BDNF, which has been related to neuroprotection and even neurogenesis. This could provide new insights into how individuals develop improved resilience to stressful or challenging situations as a result of 'resilience training' (Rothman \& Mattson, 2013). Physical training, it would appear, is intrinsi- cally linked with the physiological mechanisms required for enhanced or protective tolerance. Maintenance of physiological homeostasis and rapid return to such states underlies resilient capabilities. This may extend further to how the gastrointestinal tract interacts as part of the global system. It has been shown that athletes exhibit a greater diversity in gut bacteria (partly due to dietary intake, and partly to their level of physical exercise), compared to sedentary controls (Clarke et al. 2014). The 'cross-talk' and messaging pathways between the gut-brain axis may be a vital component in the development of enhanced resilience in the workplace.

\section{A proposal of a new conceptualisation of resil- ience in the workplace: The athlete framework of workplace resilience}

Based on the aforementioned literature we conclude that the conceptualisation of 'individual workplace resilience' should incorporate the ability to cope under pressure and an ability to return to a pre-stress state soon after the 'stressor' has occurred. It is apparent that the greater exposure to stress/challenge/overload relates to a potentially higher capacity for overall mental toughness. However, mental toughness alone does not necessarily lead to enhanced resilience. It would therefore seem that another key component of individual resilience lies in the physical status of the individual in terms of optimising health, fitness, and recovery. In many respects the overlap between physiological adaptations to stress and physical health could well underlie psychological capability or coping approaches. A more positive, less (physically) strained individual may well tolerate a higher level of challenge when faced with it. This could be likened to the impact of exercise on health parameters, and indeed the physical tolerance imposed on athletes in training. The ability to train the physical systems of the human body to higher 'tolerance states' through improved or more efficient physiological states may well lead to higher resilience on an individual level. The 'athletic employee' (i. e., elite athlete such as an Olympian) is one who is both physically and psychological trained to cope with brief periods of extreme pressure and then swiftly recover, the elite athlete can therefore be considered as an individual who has high levels of resilience.

We therefore conceptualise individual workplace resilience as a person's capacity to manage or overcome stressful, challenging or demanding states or situations at the time of experience and the capacity to minimise the risk of occupational underperformance, staleness, or burnout following exposure to stressful, challenging, or demanding periods of work. Based on our definition of resilience 'The Athlete Framework of Resilience' proposes the significant contribution of adaptive functionality as core components of acute and/or chronic ability to thrive within stressful environments (see Figure 1). 


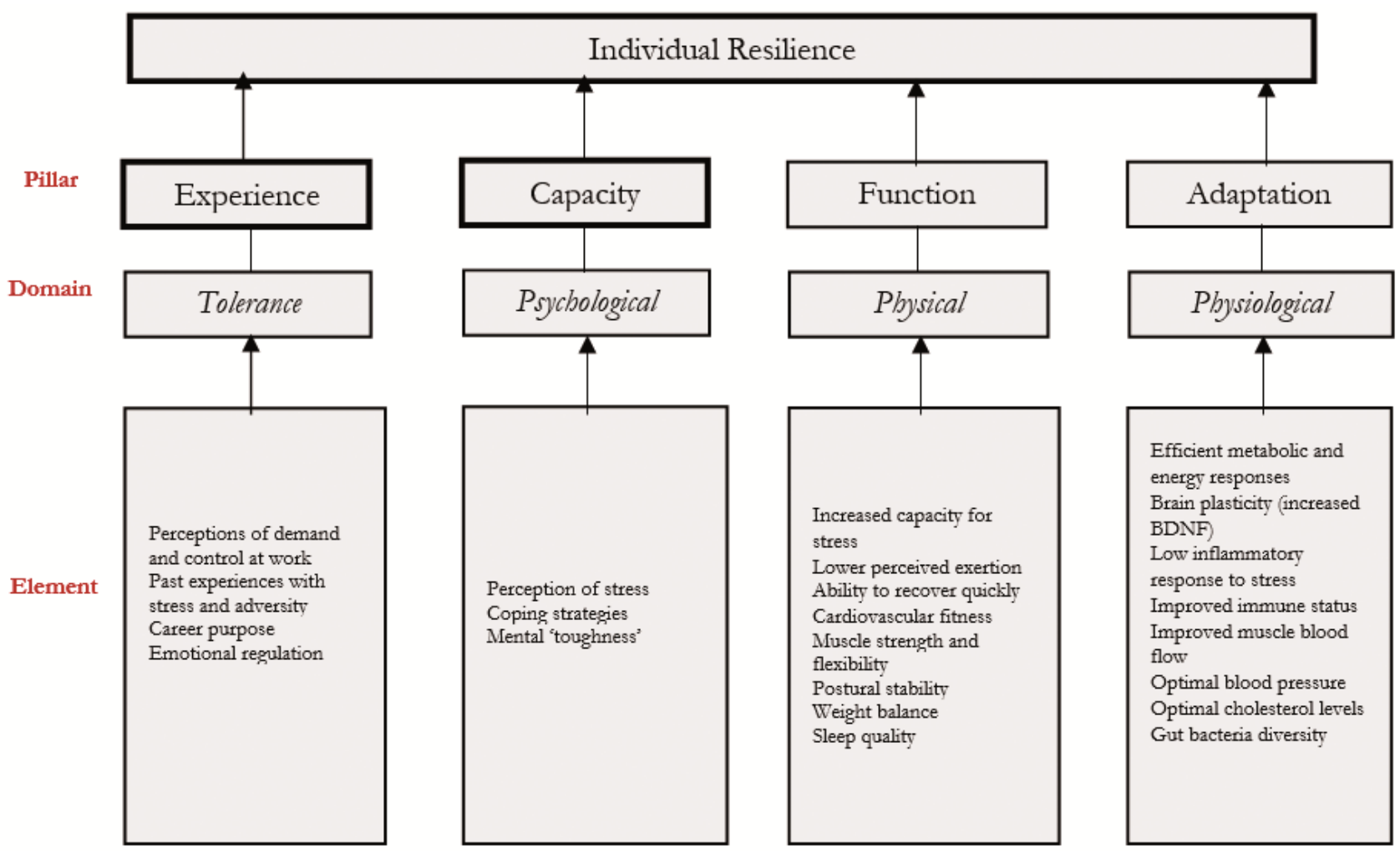

Figure 1. The Athlete Framework of Workplace Resilience.

In our framework, resilience is supported by four pillars: a person's experience of the workplace, their psychological capacity (i.e., appraisal) in relation to a challenge, the functioning of their physical organism, and the adaptation capability. By experience we mean the individual's tolerance towards stressors. As outlined previously, research has found that a person's perception of demand and control at work (Karasek \& Theorell, 1990), their collected experiences of common stressors at work and how to function in a balanced manner (Luthans et al., 2007), and their positive attitude and emotion regulation abilities (Cartwright \& Cooper, 2009) impact on the extent to which a person tolerates adversity and bounces back quickly. The capacity pillar refers to the psychological domain. As outlined in the section on Psychophysiology, the development of mental toughness in conjunction with appraisal (threat and challenge) and coping activities of the individual impact on psychological and physiological responses that either maintain or impair healthy functioning (particularly cardiovascular and endocrine aspects of health). The third element of individual workplace resilience relates to the functioning of the individual's organism. Their cardiovascular fitness, muscle strength/flexibility, postural stability (physical activity aspects, see Smith, 2003a), their weight (see e.g., Smith et al., 2015), and opportunities for physical recovery (e.g., sleep quality; von Bonsdorff et al., 2017) will impact on the extent to which the individual is functioning well during a challenging time. To what extent the individual then can adapt over time is determined and can be measured through physiological aspects of their functioning; that is efficient metabolic and energy responses, brain plasticity (increased BDNF), low inflammatory response to stress, optimal immune status, optimal muscle blood flow, optimal blood pressure, optimal cholesterol levels, and gut bacteria diversity.

We believe that all the elements need to be in place for an individual to achieve optimal adaptive functionality. Current research indicates that chronic stress (e.g., workplace demands) may be a central factor leading to physiological dysregulation of key systems of the body (e.g., metabolic, hormonal, immune). Such 'dysregulation' may play a central role in development of poor health and chronic disorders, leading to lower resilient states, reduced ability to recover from an acute stressor, and amalgamated maladaption (likened to chronic fatigue syndrome; Shephard, 2001). Physical fitness may provide a mechanistic 'buffer' to dealing with stress as it improves physical health (function) and physiological efficiency (adaptability). The optimisation of the systems of the body provides a physiological reserve or ability to tolerate higher loads.

Here, it is important to mention that we do not see an individual as resilient versus not resilient. It is a continuum as different elements might change over time and dynamically interact with another. What ideal resilience profiles (benchmarks for different elements) might look like needs to be explored in future research and might indeed differ across different population groups. Future research should also ex- 
plore in detail how the different pillars and elements interact. Whilst the previous experience to 'stress' or trauma cannot be ignored, there may well be an integrative pattern between the four pillars presented. It may be that resilience as a complex model comprises attributes from each pillar in a unique individual pattern. However, there may well be interactive patterns between pillars as well. An improved physical state through exercise training may likely impact on physiological as well as psychological responses to a challenge situation and to explain how. Higher tolerance/resilience may also be associated with a greater degree of previous experiences, if the individual has a developed a positive forward momentum with their experiential learning. Indeed, future research should create a comprehensive review of all known elements that are linked to resilience in each of the outlined domains. Here, we provided a brief scope of existing knowledge and identified gaps in the current knowledge on a comprehensive understanding of human functioning and in particular work-

\section{References}

Blascovich, J., \& Mendes, W. B. (2000). Challenge and threat appraisals: The role of affective cues. In J. P. Forgas (Ed.), Feeling and thinking: The role of affect in social cognition (pp. 59-82). Cambridge, England: Cambridge University Press.

Cartwright, S., \& Cooper, C. L. (2009). The Oxford Handbook of Organizational Well-Being. Oxford, England: Oxford University Press.

Castellano-Tejedor, C., Blasco-Blasco, T., Pérez-Campdepadrós, M., \& Capdevila-Ortís, L. (2014). Making sense of resilience: a review from the field of pediatric psycho-oncology and a proposal of a model for its study. Anales de Psicología, 30(3), 865-877. doi: 10.6018/analesps.30.3.154581

Clarke, S., Murphy, E., O’Sullivan, O., Lucey, A., Humphreys, M., Hogan, A.,..., Cotter, P. D. (2014). Exercise and associated dietary extremes impact on gut microbial diversity. Gut, 63, 1913-1920. doi: 10.1136/gutjnl-2013-306541

Daniels K. (2011). Stress and well-being are still issues and something still needs to be done: Or why agency and interpretation are important for policy and practice. In: G. P. Hodgkinso \& J. K. Ford (Eds.), Review of Industrial and Organizational Psychology (pp.1-45). Chichester, England: John Wiley\& Sons.

Demerouti, E., Bakker, A. B., Nachreiner, F., \& Schaufeli, W. B. (2001). The job demands- resources model of burnout. Journal of Applied Psychology, 86, 499-512. doi: 10.1037/0021-9010.86.3.499

Depres, J. P. (2006). Abdominal obesity: the most prevalent cause of the metabolic syndrome and related cardiometabolic risk. European Heart Journal Supplements, 8(Sb), B4-B12. doi: 10.1093/eurheartj/sul002.

Dewe, P., \& Cooper, C. (2012). Well-being and work. Towards a balanced agenda. Basingstoke, England: Palgrave MacMillan.

Dienstbier, R. A. (1989). Arousal and Physiological Toughness: Implications for Mental and Physical Health. Psychological Review, 96(1), 84-100. doi: 10.1037/0033-295X.96.1.84

Diener, E. (1994). Assessing subjective well-being: Progress and opportunities. Social Indicators Research, 31, 103-157. doi: 10.1007/BF01207052

Doring, T., Vieweger, A., Pautasso, M., Vaarst. M., Finckh, M., \& Wolfe, M. (2015). Resilience as a universal criterion of health. Journal of the Science of Food and Agriculture, 95, 455-465. doi: 10.1002/jsfa.6539

Friborg, O., Hjemdal, O., Rosenvinge, J. H., \& Martinussen, M. (2003). A new rating scale for adult resilience: What are the central protective resources behind healthy adjustment? International Journal of Methods in Psychiatric Research, 12, 65-76. doi: 10.1002/mpr.143

Fredrickson, B. L. (2001). The Role of Positive Emotions in Positive Psychology: The Broaden-and-Build Theory of Positive Emotions. American Psychologist, 56, 218-226. doi: 10.1037/0003-066X.56.3.218 place resilience. Based on our framework, resilience interventions could focus on creating a healthy body supported through high-performance physical training and nutrition in addition to a healthy mind in order to support healthy functioning.

\section{Conclusions}

Resilience can be seen as a key characteristic of a successful employee in today's turbulent work environment. In order to be able to create impactful interventions that create resilient employees, we integrated cross-disciplinary approaches to individual resilience in order to better understand the mechanism of why some people bounce back from adverse events whereas others' well-being declines. In our Athlete Framework of Workplace Resilience, we conceptualise resilience as a dynamic process that is based on four pillars that create optimal adaptive functionality.

Groppel, J. (2000). The Corporate Atblete. New York, NY: John Wiley and Sons.

Hackman, J. R., \& Oldham, G. R. (1975). Development of the job diagnostic survey. Journal of Applied Psychology, 60(2), 159-170. doi: 10.1037/h0076546

Halson, S., Lancaster, G., Jeukendrup, A., \& Gleeson, M. (2003). Immunological responses to overreaching in cyclists. Medicine and Science in Sports and Exercise, 35(5), 854-861. doi 10.1249/01.MSS.0000064964.80040.E9

Hamer, M., Endrighi, R., Venuraju, S. M., Lahiri, A., \& Steptoe, A. (2012). Cortisol Responses to Mental Stress and the Progression of Coronary Artery Calcification in Healthy Men and Women. PLOS One, 7(2), e31356. doi: 10.1371/journal.pone.0031356

Health \& Safety Executive (2016). Work related stress, anxiety and depression statistics in Great Britain 2016. Retrieved from http://www.hse.gov.uk/statistics/causdis/stress/

Herzberg, F. (1959). The motivation to work. New York, NY: John Wiley and Sons.

Hobfoll, S. E., Hall, B. J., Canetti-Nisim, D., Galea, S., Johnson, R. J., \& Palmieri, P. A. (2007). Refining our understanding of traumatic growth in the face of terrorism: Moving from meaning cognitions to doing what is meaningful. Applied Psychology: An International Review, 56(3), 345-366. doi: 10.1111/j.1464- 0597.2007.00292.x

Hobfoll, S. E. (1989). Conservation of resources: A new attempt at conceptualizing stress. American Psychologist, 44(3), 513-524. doi: 10.1037/0003066X.44.3.513

Irwin, M., \& Vedhara, K. (2005). Human Psychoneuroimmunology. Oxford, England: Oxford University Press.

Issurin, V. (2010). New horizons for the methodology and physiology of training periodization. Sports Medicine, 40(3), 189-206. doi: 10.2165/11319770-000000000-00000

Jackson, D., Firtko, A., \& Edenborough, M. (2007). Personal resilience as strategy for surviving and thriving in the face of workplace adversity: A literature review. Journal of Advanced Nursing, 60, 1-9. doi: 10.1111/j.1365- 2648.2007.04412.x

Johnson, J. V., \& Hall, E. M. (1988). Job strain, work place social support, and cardiovascular disease: A cross-sectional study of a random sample of the Swedish working population. American Journal of Public Health, 78(10), 1336-1342. doi: 10.2105/ajph.78.10.1336

Jones, G. (2002). What is this thing called mental toughness? An investigation of elite sport performers. Journal of Applied Sport Psychology, 14, 205218. doi: 10.1080/10413200290103509 
Karasek, R., \& Theorell, T. (1990). Healtby work: Stress, productivity, and the reconstruction of working life. NewYork, NY: Basic Books.

Kelli, H. M., Kassas, I., \& Lattouf, O. (2015). Cardio metabolic syndrome: a global epidemic. Journal Diabetes Metabolism, 6(513), 1-14. doi: 10.4172/2155-6156.1000513

King, D. D., Newman, A., \& Luthans, F. (2016). Not if, but when we need resilience in the workplace. Journal of Organizational Behavior, 37, 782-786. doi: 10.1002/job.2063

Leiter, M. P., \& Maslach, C. (2004). Areas of worklife: A structured approach to organizational predictors of job burnout. In P. L. Perrewe \& D. C. Ganster (Eds.), Research in occupational stress and well-being (Vol. 3, 91-134). Oxford, England: Elsevier.

Linnenluecke, M. K. (2017). Resilience in Business and Management Research: A Review of Influential Publications and a Research Agenda. International Journal of Management Reviews, 19, 4-30. doi: 10.1111/ijmr.12076

López-Sánchez, G. F., López-Sánchez, L., \& Díaz-Suárez, A. (2016). Effects of a physical activity program on the sleep quality of schoolchildren with ADHD. SPORT TK: Revista Euroamericana de Ciencias del Deporte, 5(1), 19-26.

López-Sánchez, G. F., González-Víllora, S., \& Díaz-Suárez, A. (2016). Level of habitual physical activity in children and adolescents from the Region of Murcia (Spain). SpringerPlus, 5:386, 1-6. doi: 10.1186/s40064016-2033-8

Luthans, C. (2002). Positive Organizational Behavior: Developing and Managing Psychological Strengths. Academy of Management Executive, 16(1), 57-72.

Luthans F. Youssef, C. M., \& Avolio, B. J. (2007). Psychological capital. Oxford, England: Oxford University Press.

Morgeson, F. P., \& Humphrey, S. E. (2006). The work design questionnaire (WDQ): Developing and validating a comprehensive measure for assessing job design and the nature of work. Journal of Applied Psychology, 91(6), 1321-1339. doi: 10.1037/0021-9010.91.6.1321

Office for National Statistics (2017). Measuring National Well-being. Retrieved from http://www.ons.gov.uk/ons/guide-method/user-guidance/wellbeing/index.html

Orbrist, P. A. (1976). The cardiovascular-behavioral interaction-As it appears today. Psychophysiology, 13(2), 95-107. doi:10.1111/j.14698986.1976.tb00081

Robertson, I. T., Cooper, C. L., Sarkar, M., \& Curran, T. (2015). Resilience training in the workplace from 2003 to 2014: A systematic review. Journal of Occupational and Organizational Psychology, 88(3), 533-562. doi: 10.1111 /joop. 12120

Rook, C., Hellwig, T., \& Florent-Tracy, E. (2015). Executive Stress - Taboo or Opportunity for Change? In: M. F. R. Kets de Vries, K. Korotov, E. Florent-Treacy, \& C. Rook (Eds.), Coach and Couch. The Psychology of Making Better Leaders. 2nd Ed. (pp. 230-240). Basingstoke, England: Palgrave-Macmillan.

Richardson, G. E., Neiger, B. L., Jensen, S., \& Kumpfer, K. L. (1990). The resiliency model. Health Education, 21(6), 33-39. doi: 10.1080/00970050.1990.10614589

Rothman, S., \& Mattson, M. (2013). Activity-dependent, stress-responsive BDNF signalling and the quest for optimal brain health and resilience throughout the lifespan. Neuroscience, 6(239), 228-240. doi:10.1016/j.neuroscience.2012.10.014

Salmon, P. (2001). Effects of physical exercise on anxiety, depression, and sensitivity to stress: A unifying theory. Clinical Psychology Review, 21, 3362. doi: 10.1016/S0272-7358(99)00032-X

Serrano-Gisbert, M. F., Garcés-de-Los-Fayos, E. J., \& Hidalgo-Montesinos, M. D. (2008). Burnout en fisioterapeutas españoles. Psicothema, 20(3), 361-368.
Shephard, R. (2001). Chronic Fatigue Syndrome: An update. Sports Medicine, 31(3), 167-194. doi: 10.2165/00007256-200131030-00003

Silverman, M., \& Deuster, P. (2014). Biological mechanisms underlying the role of physical fitness in health and resilience. Interface Focus, 4, 1-12. doi: $10.1098 /$ rsfs. 2014.0040

Smith, L., Ekelund, U., \& Hamer, M. (2015). The potential yield of nonexercise physical activity energy expenditure in public health. Sports Medicine, 45(4), 449-52. doi: 10.1007/s40279-015-0310-2.

Smith, L. (2003a). Overtraining, excessive exercise and altered immunity. Is this a T Helper-1 versus T Helper-2 lymphocyte response? Sports Medicine, 33(5), 347-364. doi: 10.2165/00007256-200333050-00002

Smith, D. (2003b). A framework for understanding the training process leading to elite performance. Sports Medicine, 33(15), 1103-1126. doi: 10.2165/00007256-200333150-00003

Southwick, S., \& Charney, D. (2015) Resilience: The science of mastering life's greatest challenges. Cambridge, England: Cambridge University Press.

Tlucakova, L., Ruzbarska, B., Cech, P., Kacur, P., Zvonar, M., \& Gimunova, M. (2016). Association between physical activity and body composition of high school students. SPORT TK-Revista Euroamericana de Ciencias del Deporte, 5(2), 69-75.

Tugade, M. M., \& Fredrickson, B. L. (2004). Resilient individuals use positive emotions to bounce back from negative emotional experiences. Journal of Personality and Social Psychology, 86, 320-333. doi: 10.1037/00223514.86.2.320

van der Doef, M., \& Maes, S. (1999). The job demand-control (-support) model and psychological well-being: A review of 20 years of empirical research. Work \& Stress, 13(2), 87-114. doi: 10.1037/0022-3514.86.2.320

Vespalec, T., Pavlík, J., Zvonař, M. \& Zeman, T. (2016). Physical activity of Czech schoolchildren in the autumn season. Journal of Human Sport and Exercise, 11(Proc1), S137-S145. doi:10.14198/jhse.2016.11.Proc1.04

Vespalec, T., \& Zvonař, M. (2016). Comparison of physical activity and health status in the specified focus group of population of middle-aged and older. In M. Zvonař \& Z Sajdlová (Eds.), 10th International Confer ence On Kinanthropology "Sport and Quality of Life" (pp. 216-231). Brno, Czech Republic: Masarykova Univerzita.

von Bonsdorff, M. B., Strandberg, A., von Bonsdorff M., Törmäkangas, T., Pitkälä K. H., \& Strandberg, T. E. (2017). Working hours and sleep duration in midlife as determinants of health-related quality of life among older businessmen. Age Ageing, 46(1), 108-112. doi: 10.1093 /ageing/afw178

Warr, P. (2013). Jobs and job-holders: Two sources of happiness and unhappiness. In S. David, I. Boniwell \& A. Conley Ayers (Eds.), Oxford handbook of happiness (pp. 733-750). Oxford, England: Oxford University Press.

Warr, P. (2003). Well-being and the workplace. In D. Kahnemann, E. Diener \& N. Schwarz (Eds.), Well-being. The foundations of hedonic psychology (pp. 392-412). New York, NY: Russell Sage Foundation.

Warr, P., \& Clapperton, G. (2009). The joy of work? Jobs, happiness and you. Hove, England: Routledge.

Windle, G. (2011). Psychological resilience as a resource for later life. Gerontologist, 51, 331-331. doi: 10.1093/geront/gns068

Zautra, A., Hall, J., \& Murray, K. (2008). Resilience: a new integrative approach to health and mental health research. Health Psychology Review, 2(1), 41-64. doi: 10.1080/17437190802298568

Zurita-Ortega, F., Espejo-Garcés, T., Cofré-Boladós, C., MartínezMartínez, A., Castro-Sánchez, M., \& Chacón-Cuberos, R. (2016). Influencia de la actividad física sobre la resiliencia en adultos con dolor de hombro. SPORT TK-Revista EuroAmericana de Ciencias del Deporte, 5(2), 53-58.

(Article received: 12-07-2017; revised: 02-10-2017; accepted: 19-10-2017 